\title{
Phenotyping Individuals With Newly-Diagnosed Type 2 Diabetes at Risk for All-Cause Mortality: A Single Centre Observational, Prospective Study
}

\section{Edoardo Biancalana}

University of Pisa

\section{Federico Parolini}

University of Pisa

\section{Alessandro Mengozzi \\ University of Pisa}

Anna Solini ( $\square$ anna.solini@med.unipi.it)

University of Pisa

\section{Research}

Keywords: newly-diagnosed type 2 diabetes, all-cause mortality, phenotype, metformin, renal function

Posted Date: May 21st, 2020

DOI: https://doi.org/10.21203/rs.3.rs-22027/v2

License: (a) (i) This work is licensed under a Creative Commons Attribution 4.0 International License.

Read Full License

Version of Record: A version of this preprint was published at Diabetology \& Metabolic Syndrome on May 25th, 2020. See the published version at https://doi.org/10.1186/s13098-020-00555-x. 


\section{Abstract}

Background Type 2 diabetes (T2D) shows a high mortality rate, dependent on disease duration, comorbidities and glucose control over time. Data on patients with short disease duration are scanty.

Methods We prospectively followed a cohort of newly-diagnosed T2D patients referring to a single diabetes centre, treated according to the international guidelines and checked every 6-12 months. Allcause mortality and major cardiovascular (CV) events were registered.

Results 289 patients out of 3019 consecutive first attendances matched inclusion criteria and were included in the observation. Mean follow-up was 51.2 months. At 31 December 2018, 253 patients were alive and 36 deceased. At baseline, deceased individuals were older, with lower eGFR and lower uric acid, higher prevalence of atrial fibrillation. During the follow-up, 18 non-fatal CV events were adjudicated; patients with incident CV disease (CVD) differed at baseline for sex, previous history of CVD and retinopathy, higher use of secretagogues and lower use of metformin. At multivariate analysis, age and previous CVD were the only independent determinants of all-cause mortality and incident CVD, respectively. In deceased individuals, eGFR slope was markedly unstable and $\triangle \mathrm{eGFR}$ at the end of the follow-up was higher $(p<0.001)$, and predicted mortality.

Conclusion Newly-diagnosed T2D patients followed according to the best clinical practice show a mortality rate similar to that reported in more complicated patients with longer disease duration; none of the clinical and biochemical variables commonly measured at baseline can predict mortality or incident CVD; early metformin use seems to be associated with no risk of prevalent or incident retinopathy.

\section{Background}

Type 2 diabetes (T2D) is a complex disease whose prevalence shows an alarming increasing trend; in these patients the rate of all-cause and cardiovascular (CV) mortality is several folds higher than in the general population [1-3]. Various determinants of such increased risk profile can be identified; beside the presence of comorbidities like obesity and hypertension, and the degree of glucose control and of the other risk factors $[4,5]$, a relevant role is played by the disease duration [6-8].

The all-cause and CV risk profile in newly-diagnosed T2D is, so far, insufficiently characterized. Even though in T2D the diagnosis does not correspond to the true onset of the disease, it could be conceivable to hypothesize that, initially, the all-cause and CV mortality risk would not differ so much in comparison with non-diabetic individuals. Matter of fact that some studies have shown as in the pre-diabetes states, like impaired glucose tolerance or impaired fasting glucose, or in people with new-onset T2D, the mortality risk is superimposable, and even higher, than that observed in people with overt and long-term T2D [9-12], reinforcing the importance of an early, multifactorial intervention aimed at reducing the mortality risk in these individuals. In this view, observational studies performed in a real-world context might provide interesting and useful information on the clinical and biochemical parameters marking deaths or major $\mathrm{CV}$ events occurring over a relatively short time, including the role of a very early vs a late 
start of the pharmacologic treatment [13], allowing an early identification of high-risk patients in which appropriate and timely interventions might help to reduce the risk of premature mortality. The aim of this study was to explore whether, among a cohort of patients with new-onset T2D referring to a diabetes clinic and treated according to the international guidelines for all CV risk factors, a clinical phenotype able to predict the risk of early death or occurrence of $\mathrm{CV}$ events over a relatively short follow-up (FU) could be identified.

\section{Subjects And Methods}

This observational, prospective, single centre study enrolled all the patients referring for the first time to the outpatient diabetes clinic in the department of Internal Medicine between January 2008 and June 2015 and matching the inclusion criteria, i.e. age $\geq 30$ years and personal history of known T2D lasting not more than 6 months. Main exclusion criteria were type 1 diabetes and other specific types of diabetes; acute complications of diabetes, such as diabetic ketoacidosis or lactic acidosis; autoimmune diseases; severe mental illness. Diagnosis was confirmed on the basis of the OGTT or HbA1c $\geq 6.5 \%$ plus fasting blood glucose $\geq 126 \mathrm{mg} / \mathrm{dl}$. According to such inelusion criteria, 289 patients out of $3019(9.6 \%)$ were identified and included in the prospective observation. The study protocol was approved by the Ethics Committee of the University of Pisa, and an informed consent was obtained by the participants.

Patients underwent a complete clinical examination, annotating current glucose, blood pressure (BP) and lipid lowering therapy, with indication of the class of drug. BMI was calculated, BP and vital parameters were registered, and blood samples were collected for routine analyses. Complete blood count, glucose, $\mathrm{HbA} 1 \mathrm{c}$, transaminases, uric acid, were determined by standard techniques. Plasma cholesterol and triglycerides concentrations were measured by standard enzymatic assays with commercially available kits. HDL-cholesterol was measured after precipitation of ApoB containing lipoproteins, allowing for the estimate of LDL-C by the Friedewald formula. Serum creatinine was measured by the isotope dilution mass spectrometry (IDMS) traceable method; glomerular filtration rate was estimated (eGFR) using the CKD-EPI equation. Within one week from the basal evaluation, patients underwent also an ophthalmoscopic exam (to test the presence of background or advanced retinopathy).

Previous major acute CV events, including myocardial infarction, stroke, foot ulcer/gangrene/amputation and coronary, carotid and lower limb revascularisation, were adjudicated based on hospital discharge records. Heart failure was defined as left ventricular ejection fraction $\leq 45 \%$ [14], and/or previous hospitalization for heart failure. Atrial fibrillation was adjudicated only when permanent or recurring.

\section{Follow up}

At the end of the baseline visit, patients were treated according to the good clinical practice recommended by the international guidelines, and followed a six-month or an yearly calendar of followup visits, until death or until 31 December 2018. All-cause mortality was assessed by checking the vital status of study participants on 31 December 2018; for this purpose, we interrogated the Italian Health Card database (http://sistemats1.sanita.finanze.it/wps/portal/), which provides updated information on 
all current Italian residents. Incident major acute CV events were registered on the basis of clinical records every year; retinopathy onset was assessed by fundoscopy on a yearly basis. Seven patients were excluded from such analyses due to missing information. HbA1c and eGFR slopes were built up to the end of the follow up.

\section{Statistics}

Data are expressed as mean (SD) or median (interquartile range) for continuous variables, and number of cases (percentage) for categorical variables. Continuous variables were compared using one-way ANOVA or the nonparametric Kruskal-Wallis test. The $\chi^{2}$ test was applied to categorical variables. Annual mortality rate (\%o) was calculated as the number of deaths/(population size over the follow-up period*mean duration of follow-up expressed in years) $* 10^{4}$. To assess correlations, we used univariable and multivariable logistic regression models, adjusting for confounders (sex, age, BMI, blood pressure, glycaemia, HbA1c, uric acid), reporting results as Odds Ratio [95\% C.I.]. Statistical tests were conducted using a two-sided a-level of 0.05 .

\section{Results}

Baseline clinical characteristics of the newly-diagnosed participants are shown in Table 1. Patients were adequately distributed for sex. Smoking habits were highly prevailing in males. Women were more obese and showed a worse lipid profile; however, LDL cholesterol was far from being at target $(<100 \mathrm{mg} / \mathrm{dl}$ in primary prevention according to international guidelines) in both sexes. $25.3 \%$ of the study group showed a scarce metabolic control ( $\mathrm{HbA} 1 \mathrm{c}>8 \%)$, with no sex difference in fasting blood glucose or HbA1c. Renal function was similar in men and women; $13.2 \%$ of patients were already in a CKD stage $\geq 3$ according to eGFR. Retinopathy was present only in seven patients, all males.

On the basis of clinical records, a previous CV event was confirmed in $15 \%$ of the patients, with a significant prevalence in the male sex. Prevalence of heart failure and atrial fibrillation was $7 \%$ and $8 \%$, respectively.

Table 1 Clinical and biochemical characteristics of the study cohort at baseline. 


\begin{tabular}{|c|c|c|c|c|}
\hline & $\begin{array}{l}\text { All } \\
289\end{array}$ & $\begin{array}{c}\text { Men } \\
158(54.7 \%)\end{array}$ & $\begin{array}{c}\text { Women } \\
131(45.3 \%)\end{array}$ & $\mathrm{p}$ value \\
\hline Age (yrs) & $63.3 \pm 11.0$ & $62.7 \pm 12.0$ & $64.0 \pm 11.0$ & ns \\
\hline Ethnic group (caucasian/black/Asian; \%) & $95 / 2 / 3$ & $94 / 3 / 3$ & $97 / 1 / 2$ & ns \\
\hline High School education or above (n; \%) & $101 ; 34.9$ & $53 ; 33.5$ & $48 ; 36.6$ & ns \\
\hline BMI $\left(\mathrm{Kg} / \mathrm{m}^{2}\right)$ & $30.5 \pm 6.0$ & $29.5 \pm 5.3$ & $31.7 \pm 6.5$ & 0.0026 \\
\hline Smoking habits (yes/no/ex; \%) & $11 / 51 / 38$ & $15 / 38 / 47$ & $5 / 69 / 26$ & $<0.001$ \\
\hline SBP (mmHg) & $141.0 \pm 19.7$ & $140.0 \pm 19.4$ & $142.2 \pm 20.3$ & ns \\
\hline $\mathrm{DBP}(\mathrm{mmHg})$ & $83.0 \pm 11.0$ & $83.1 \pm 11.0$ & $83.0 \pm 11.1$ & ns \\
\hline Fasting glucose $(\mathrm{mg} / \mathrm{dL})$ & $158 \pm 57$ & $158 \pm 60$ & $157 \pm 54$ & ns \\
\hline Hb1Ac (\%) & $7.6 \pm 1.7$ & $7.6 \pm 1.64$ & $7.7 \pm 1.8$ & ns \\
\hline Patients with HbA1c >8\% (n; \%) & $73 ; 25.3$ & $43 ; 27.2$ & $30 ; 22.9$ & ns \\
\hline Total cholesterol (mg/dL) & $202 \pm 43$ & $192 \pm 41$ & $214 \pm 44$ & $<0.0001$ \\
\hline HDL-cholesterol (mg/dL) & $48 \pm 16$ & $43 \pm 11$ & $55 \pm 18$ & $<0.0001$ \\
\hline LDL-cholesterol (mg/dL) & $122 \pm 42$ & $114 \pm 42$ & $131 \pm 41$ & 0.0022 \\
\hline Triglycerides (mg/dL) & $169 \pm 106$ & $179 \pm 115$ & $157 \pm 92$ & ns \\
\hline ALT (IU/L) & $32 \pm 22$ & $34 \pm 25$ & $30 \pm 19$ & ns \\
\hline AST (IU/L) & $24 \pm 13$ & $26 \pm 13$ & $23 \pm 12$ & ns \\
\hline$\gamma \mathrm{GT}(\mathrm{IU} / \mathrm{L})$ & $50 \pm 59$ & $57 \pm 73$ & $43 \pm 36$ & ns \\
\hline Serum creatinine $(\mathrm{mg} / \mathrm{dL})$ & $0.95 \pm 0.41$ & $1.1 \pm 0.45$ & $0.77 \pm 0.16$ & $<0.0001$ \\
\hline eGFR CKD-EPI $\left(\mathrm{ml} / \mathrm{min} / 1.73 \mathrm{~m}^{2}\right)$ & $79.2 \pm 21.0$ & $77.3 \pm 23.0$ & $81.5 \pm 18.0$ & ns \\
\hline eGFR $<60 \mathrm{ml} / \mathrm{min} / 1.73 \mathrm{~m}^{2}$ (n; \%) & $38 ; 13.2$ & $23 ; 14.6$ & $15 ; 11.5$ & ns \\
\hline Uric acid (mg/dL) & $6.0 \pm 1.8$ & $6.3 \pm 1.8$ & $5.6 \pm 1.5$ & ns \\
\hline Diabetic retinopathy (n; \%) & $7 ; 2.4$ & $7 ; 4.4$ & $0 ; 0$ & 0.022 \\
\hline Previous CV disease $(\mathrm{n} ; \%)$ & $44 ; 15.2$ & $37 ; 23.4$ & $7 ; 5.3$ & $<0.0001$ \\
\hline Heart failure $(\mathrm{n} ; \%)$ & $19 ; 6.6$ & $12 ; 7.6$ & $7 ; 5.3$ & ns \\
\hline Atrial fibrillation (n; \%) & $23 ; 8.0$ & $15 ; 9.5$ & $8 ; 6.1$ & ns \\
\hline Any cancer (n; \%) & $50 ; 17.5 \%$ & $23 ; 14.6 \%$ & $27 ; 21.1 \%$ & ns \\
\hline
\end{tabular}

Table 2 shows the initial distribution of the pharmacologic treatments. At baseline visit, $54 \%$ of patients did not assume any treatment for diabetes. Metformin (mean dose $1000 \mathrm{mg} / \mathrm{die}$ ) was already on board in one-third of the patients, while $17.3 \%$ of them received secretagogues, alone or in combination with metformin; in these latter, $\mathrm{HbA} 1 \mathrm{c}$ was significantly higher vs those not receiving the drugs $(8.1 \pm 2.0 \mathrm{vs}$ $7.3 \pm 1.3 \%, p=0.012$ ). Sixty-two percent of the patients received anti-hypertensive treatment; despite the insufficient control of lipid levels, only $30 \%$ of the patients were on statin treatment.

Table 2 Pharmacologic treatment of the study cohort at baseline 


\begin{tabular}{|l|c|c|c|c|}
\hline & $\begin{array}{c}\text { All } \\
289\end{array}$ & $\begin{array}{c}\text { Men } \\
158(54.7 \%)\end{array}$ & $\begin{array}{c}\text { Women } \\
131(45.3 \%)\end{array}$ & p value \\
\hline No treatment (n; \%) & $155 ; 53.6$ & $81 ; 51.3$ & $74 ; 56.5$ & $\mathrm{~ns}$ \\
\hline Metformin (n; \%) & $84 ; 29.1$ & $48 ; 30.4$ & $36 ; 27.5$ & $\mathrm{~ns}$ \\
\hline Secretagogues ( \pm metformin; $;$ \%) & $50 ; 17.3$ & $29 ; 18.4$ & $21 ; 16.0$ & $\mathrm{~ns}$ \\
\hline Anti-hypertensive treatment (n; \%) & $179 ; 61.9$ & $103 ; 65.2$ & $76 ; 58.0$ & $\mathrm{~ns}$ \\
\hline Statins (n; \%) & $88 ; 30.4$ & $50 ; 31.6$ & $38 ; 29.0$ & $\mathrm{~ns}$ \\
\hline
\end{tabular}

\section{Follow up}

Mean duration of the follow up was 51.2 months (median: 49 months); during such observation, we registered 36 deaths ( $12.5 \%$ of the study population). The mortality rate in this cohort was $29.2 \%$ o/year. Table 3 shows the baseline phenotype of patients alive or deceased at the index date. Patients encountering exitus within four years from the diagnosis of T2D were older, had a remarkably lower eGFR, lower uric acid levels, and a higher prevalence of atrial fibrillation. No significant differences emerged in the distribution of the treatments for T2D and comorbidities, as well as in the mean $\mathrm{HbA1c}$, even though in the group of deceased patients there was a significant greater percentage of patients with impaired glycaemic control ( $\mathrm{HbA} 1 \mathrm{c}>8 \%)$ at baseline. After multivariate analysis, age at diagnosis remained as the only basal predictor of all-cause mortality.

\section{Role of the renal phenotype}

Glomerular function strongly influences the prognosis in T2D; even though eGFR was not an independent predictor of all cause-mortality in this cohort of patients with short T2D duration, we explored its behaviour over time by building up the slopes on the basis of serum creatinine measured every six months, and relating them to all-cause mortality. Data are shown in Figure 1a; interestingly, $\triangle$ eGFR at 52 months was significantly higher in deceased individuals $\left(-6.9 \pm 3.8 \mathrm{vs}+2.5 \pm 0.1 \mathrm{ml} / \mathrm{min} / 1.73 \mathrm{~m}^{2}, p<0.001\right)$; moreover, eGFR slope in these subjects was markedly unstable, with ample oscillations over the observation period (SD: 6.3 [4.8-12.3] vs $5.6[3.5-8.5] \mathrm{ml} / \mathrm{min} / 1.73 \mathrm{~m}^{2}$ ); the slope of alive individuals remained virtually stable. In the multivariate analysis, $\triangle$ eGFR emerged as significant determinant of mortality (OR 1.14 [1.01-1.43], $\mathrm{p}=0.0453$ ) also when adjusted for confounders (sex, age, BMI, blood pressure, glycaemia, HbA1c, uric acid). We also checked the impact of metabolic control over time, but the mean $\mathrm{HbA} 1 \mathrm{c}$ value registered during the whole follow up (mean 6.3 determinations/patient) did not differently marked deceased vs surviving individuals (Figure 1b).

Table 3 Baseline phenotype and treatments of patients deceased or alive over the follow up 


\begin{tabular}{|c|c|c|c|}
\hline & $\begin{array}{c}\text { Deceased } \\
36(12.8 \%)\end{array}$ & $\begin{array}{c}\text { Alive } \\
253(87.2 \%)\end{array}$ & $\mathrm{p}$ value \\
\hline Age (yrs) & $72.8 \pm 9.0$ & $61.9 \pm 11.3$ & $<0.0001$ \\
\hline Sex (n; \%) & $\begin{array}{l}\text { F } 14(38.9 \%) \\
\text { M } 22(61.1 \%)\end{array}$ & $\begin{array}{l}\text { F } 117(46.2 \%) \\
\text { M } 136(53.8 \%)\end{array}$ & ns \\
\hline $\mathrm{BMI}\left(\mathrm{Kg} / \mathrm{m}^{2}\right)$ & $30.0 \pm 5.8$ & $30.6 \pm 6.0$ & ns \\
\hline SBP (mmHg) & $145.6 \pm 19.8$ & $140.3 \pm 19.7$ & ns \\
\hline DBP (mmHg) & $84.8 \pm 11.3$ & $82.8 \pm 11.0$ & ns \\
\hline Fasting glucose (mg/dL) & $156 \pm 50$ & $158 \pm 59$ & ns \\
\hline Hb1Ac (\%) & $7.9 \pm 1.3$ & $7.6 \pm 1.8$ & $\mathrm{~ns}$ \\
\hline Patients with HbA1c >8\% (n; \%) & $15 ; 45.5$ & $58 ; 25.5$ & 0.0174 \\
\hline Total cholesterol (mg/dL) & $196 \pm 40$ & $203 \pm 44$ & ns \\
\hline HDL-cholesterol (mg/dL) & $51 \pm 14$ & $48 \pm 16$ & ns \\
\hline LDL-cholesterol (mg/dL) & $122 \pm 53$ & $122 \pm 41$ & $\mathrm{~ns}$ \\
\hline Triglycerides (mg/dL) & $136 \pm 75$ & $173 \pm 108$ & ns \\
\hline$\overline{\mathrm{ALT}}(\mathrm{IU} / \mathrm{L})$ & $25 \pm 12$ & $33 \pm 23$ & ns \\
\hline AST (IU/L) & $21 \pm 7$ & $25 \pm 13$ & ns \\
\hline$\gamma \mathrm{GT}(\mathrm{IU} / \mathrm{L})$ & $44 \pm 28$ & $51 \pm 62$ & $\mathrm{~ns}$ \\
\hline Serum creatinine $(\mathrm{mg} / \mathrm{dL})$ & $1.06 \pm 0.6$ & $0.93 \pm 0.37$ & ns \\
\hline eGFR CKD-EPI (ml/min/1.73m²) & $70.6 \pm 19.2$ & $81.0 \pm 20.0$ & 0.0256 \\
\hline eGFR $<60 \mathrm{ml} / \mathrm{min} / 1.73 \mathrm{~m}^{2}(\mathrm{n} ; \%)$ & $8 ; 22.2$ & $30 ; 11.9$ & ns \\
\hline Uric acid $(\mathrm{mg} / \mathrm{dL})$ & $4.9 \pm 1.1$ & $6.2 \pm 0.2$ & 0.0291 \\
\hline Diabetic retinopathy $(\mathrm{n} ; \%)$ & $1 ; 2.8 \%$ & $6 ; 2.4$ & $\mathrm{~ns}$ \\
\hline Previous CV disease (n; \%) & $6 ; 16.7$ & $38 ; 15.0$ & $\mathrm{~ns}$ \\
\hline Heart failure (n; \%) & $4 ; 11.1$ & $15 ; 5.9$ & ns \\
\hline Atrial fibrillation (n; \%) & $6 ; 16.7$ & $17 ; 6.7$ & 0.0067 \\
\hline Any cancer (n; \%) & $10 ; 27.8$ & $40 ; 15.8$ & $\mathrm{~ns}$ \\
\hline No treatment (n; \%) & $16 ; 44.4$ & $139 ; 54.9$ & ns \\
\hline Metformin (n; \%) & $12 ; 33.3$ & $72 ; 28.5$ & ns \\
\hline Secretagogues (n; \%) & $8 ; 22.2$ & $42 ; 16.6$ & ns \\
\hline Anti-hypertensive treatment (n; \%) & $23 ; 63.9$ & $156 ; 61.6$ & $\mathrm{~ns}$ \\
\hline Statins $(\mathrm{n} ; \%)$ & $14 ; 38.9$ & $74 ; 29.2$ & $\mathrm{~ns}$ \\
\hline
\end{tabular}

\section{Phenotype and incident CV events}

Table 4 compares the baseline phenotype of people developing or not an acute CV event over the follow up; seven missed patients were excluded from this analysis. We registered 18 new CV events; $50 \%$ of 
them were first episodes, and 50\% recurrent events. Only 3 events occurred in patients deceased during the follow-up, while the remaining were surely non-fatal events. Clinical characteristics marking such events were the male sex, the previous personal history of CV disease and retinopathy and, interestingly, a relative delay in the time of starting the antidiabetic treatment; in detail, macrovascular events occurred in a significantly higher percentage in patients not pharmacologically treated since the very beginning of the disease, or in those receiving sulphonylureas. As expected, multivariate analysis identified previous CV events (OR 21.51 [1.37-338], $p=0.0097$ ) as the only independent predictor of future CV events in such study cohort; predictive elements for incident CVD in people with no previous personal history were undetectable.

Table 4 Baseline phenotype of patients developing or not developing acute CV events over the follow up (seven missing patients excluded from the analysis) 


\begin{tabular}{|c|c|c|c|}
\hline & $\begin{array}{c}\text { New CV events } \\
18(6.4 \%)\end{array}$ & $\begin{array}{c}\text { No new CV events } \\
264(93.6 \%)\end{array}$ & p value \\
\hline Age (yrs) & $66.6 \pm 8,0$ & $63.0 \pm 11,8$ & ns \\
\hline Sex (n; \%) & $\begin{array}{rl}\mathrm{F} & 3 ; 16.6 \% \\
\mathrm{M} & 15 ; 83.2 \%\end{array}$ & $\begin{array}{ll}\mathrm{F} & 122 ; 46.2 \% \\
\mathrm{M} & 142 ; 53.8 \%\end{array}$ & 0.0146 \\
\hline BMI $\left(\mathrm{Kg} / \mathrm{m}^{2}\right)$ & $28.7 \pm 5.0$ & $30.5 \pm 5.9$ & ns \\
\hline SBP (mmHg) & $142.7 \pm 21.2$ & $140.5 \pm 19.7$ & ns \\
\hline DBP (mmHg) & $81.4 \pm 10.4$ & $83.0 \pm 11.0$ & ns \\
\hline Fasting glucose (mg/dL) & $138 \pm 51$ & $159 \pm 58$ & ns \\
\hline Hb1Ac (\%) & $7.25 \pm 1.0$ & $7.68 \pm 1.75$ & $\mathrm{~ns}$ \\
\hline Total cholesterol (mg/dL) & $185 \pm 29$ & $203 \pm 43$ & ns \\
\hline HDL-cholesterol (mg/dL) & $43 \pm 11$ & $48 \pm 14$ & ns \\
\hline LDL-cholesterol (mg/dL) & $114 \pm 27$ & $123 \pm 43$ & $\mathrm{~ns}$ \\
\hline Triglycerides (mg/dL) & $140 \pm 49$ & $170 \pm 108$ & ns \\
\hline ALT (IU/L) & $25 \pm 9$ & $32 \pm 23$ & ns \\
\hline AST (IU/L) & $23 \pm 4$ & $25 \pm 13$ & ns \\
\hline$\gamma \mathrm{GT}(\mathrm{IU} / \mathrm{L})$ & $41 \pm 25$ & $50 \pm 60$ & $\mathrm{~ns}$ \\
\hline Serum creatinine $(\mathrm{mg} / \mathrm{dL})$ & $1.07 \pm 0.3$ & $0.94 \pm 0.42$ & ns \\
\hline eGFR CKD-EPI (ml/min/1.73m²) & $71.8 \pm 17.3$ & $80.0 \pm 21.2$ & ns \\
\hline eGFR $<60 \mathrm{ml} / \mathrm{min} / 1.73 \mathrm{~m}^{2}(\mathrm{n} ; \%)$ & $3 ; 16.7$ & $34 ; 12.9$ & ns \\
\hline Uric acid (mg/dL) & $6.6 \pm 1.2$ & $5.9 \pm 1.8$ & ns \\
\hline Previous CV disease (n; \%) & $9 ; 50.0$ & $33 ; 12.5$ & $<0.0001$ \\
\hline Heart failure (n; \%) & $3 ; 16.7$ & $15 ; 5.7$ & ns \\
\hline Atrial fibrillation (n; \%) & $1 ; 5.6$ & $22 ; 8.3$ & ns \\
\hline Any cancer $(\mathrm{n} ; \%)$ & $5 ; 27.8$ & $45 ; 17.0$ & $\mathrm{~ns}$ \\
\hline Diabetic retinopathy (n; \%) & $3 ; 16.7$ & $4 ; 1.5$ & $<0.0002$ \\
\hline No treatment (n; \%) & $8 ; 44.4$ & $143 ; 54.2$ & 0.0400 \\
\hline Metformin (n; \%) & $3 ; 16.7$ & $79 ; 29.9$ & \\
\hline Secretagogues (n; \%) & $7 ; 38.9$ & $42 ; 15.9$ & \\
\hline Anti-hypertensive treatment (n; \%) & $13 ; 72.2$ & $160 ; 60.1$ & $\mathrm{~ns}$ \\
\hline Statins $(n ; \%)$ & $7 ; 41.1 \%$ & $76 ; 29.0 \%$ & $\mathrm{~ns}$ \\
\hline
\end{tabular}

Table 5 shows the prevalence of macrovascular complications and retinopathy at baseline and at the end of the observation period, according to baseline treatment for T2D. Early use of metformin was coupled, 
even in this small cohort, to less incidence of CV events over the follow up. Of note, no retinopathy was present at diagnosis, neither developed at follow up $(n=13)$, in patients starting an early treatment with metformin.

Table 5 Patients with CVD, retinopathy and CKD stage $\geq 3$ at baseline and at the end of the follow up according to treatment of T2D at baseline (seven missing patients excluded from the analysis)

\begin{tabular}{|l|c|c|c|c|c|}
\hline & All & $\begin{array}{c}\text { No treatment } \\
148(53.6 \%)\end{array}$ & $\begin{array}{c}\text { Metformin } \\
84(29.1 \%)\end{array}$ & $\begin{array}{c}\text { Secretagogues } \\
50(17.3 \%)\end{array}$ & v value \\
\hline Baseline CV disease (n; \%) & 44 & $26 ; 17.6$ & $9 ; 10.7$ & $9 ; 18$ & ns \\
\hline Follow up CV disease (n; \%) & 18 & $8 ; 5.4$ & $3 ; 3.6$ & $7 ; 14.0$ & 0.04 \\
\hline Baseline any retinopathy (n; \%) & 7 & $3 ; 2.0$ & $0 ; 0$ & $4 ; 8.0$ & 0.015 \\
\hline Follow up any retinopathy (n; \%) & 13 & $7 ; 4.7$ & $0 ; 0$ & $6 ; 12$ & 0.007 \\
\hline Baseline CKD stage $\geq 3$ & 38 & $21 ; 14.2$ & $9 ; 10.7$ & $8 ; 16.0$ & $\mathrm{~ns}$ \\
\hline Follow up CKD stage $\geq 3$ & 17 & $9 ; 6.1$ & $2 ; 2.4$ & $6 ; 12$ & $\mathrm{~ns}$ \\
\hline
\end{tabular}

\section{Discussion}

The main results of our single-centre, real-life prospective observation can be summarized as follows: $i$ ) in a cohort of newly-diagnosed T2D individuals, the mortality rate in the first years after the diagnosis does not differ from that reported in large cohorts of patients with longer disease duration; ii) a quite large panel of clinical and biochemical variables at baseline does not allow to predict mortality or incident CVD; iii) early metformin use seems to be associated with no risk of prevalent or incident retinopathy.

Real-life observations performed in large cohorts of T2D individuals indicate a variable mortality rate, higher in the Western countries [15-17] and lower in Arab countries [18], and declining over the last decade [19]; diabetes duration is, indeed, one of the main determinants of such risk [20,21]. In our small sample we show that, despite the intensive treatment of all risk factors and comorbidities, the mortality rate of the patients over the first five years of known disease is superimposable to that of patients with much higher diabetes duration and prevalence of comorbidities, confirming the relative weight of prediabetes state in determining a higher CV and, of less extent, mortality risk [10, 22, 23]. Another possibility could be a short-term negative effect on mortality that follows the diagnosis of diabetes in older adults; such phenomenon was not reported in the large subset of the Kaiser Permanente Northern California with the same age of our patients and a short diabetes duration, where the mortality rate was 19.61/1000 patients/year [24]. This early, relatively high mortality risk is compelling, because implies that even a briefly exposure to hyperglycaemia could elicit detrimental effects, and that macrovascular damage through atherosclerotic pathways may not be primarily responsible. 
The alarming picture is made even worse by the lack of any predictive value on the short-term mortality of an ample panel of clinical and biochemical routine variables, like metabolic control and previous CVD. Age at diagnosis was, actually, the only independent predictor; its prognostic implications have been recently pointed out in a key report from the Swedish National Diabetes Registry [25], and reinforces the need for a capillary screening and an early identification of any derangement of glucose tolerance, hoping that an early treatment aimed at targeting the various risk factors would be able to reduce the mortality risk in such individuals. Moreover, in this small cohort of individuals adequately treated for concomitant risk factors, incident $\mathrm{CV}$ events have not been easily predictable in those without previous personal history of CVD, pointing out an urgent need for finding novel, easily-measured, reliable biomarkers.

Interestingly, in these subjects an early use of metformin seems to be associated with absence of retinopathy over the whole observation period. Recent retrospective observations in patients with longer disease duration have documented a reduced severity of retinopathy in those receiving metformin [26]. Metformin was found effective also in protecting toward other forms of eye involvement in T2D [27, 28]; it should be also pointed out as, in the Diabetes Prevention Program Outcomes Study, prolonged metformin treatment in subjects with pre-diabetes did reduce the incidence of T2D, but not of the aggregate microvascular outcome [29]. Prospective real-life data in patients with short disease duration are scanty; our observation, that need to be confirmed on larger numbers, seems to support the idea that an early use of metformin might protect the eye, likely because it does not induce hypoglycaemia, detrimental toward the retina [30], or - alternatively - by exerting endothelial protection [31].

Trend of eGFR in our study cohort deserves a comment, being the delta between basal and final value significantly higher in T2D patients encountering death over the follow-up; even more, multivariate analysis confirmed it as predictor of mortality. This supports the notion that a fast decline of glomerular filtration, even in subjects with short duration of T2D and preserved renal function, is a main factor affecting the short as well as long-term prognosis [32,33], reinforcing the need for early therapeutic strategies of nephroprotection.

We should acknowledge several limitations of the present study: the small cohort, the lack of data on albuminuria (according to guidelines and good clinical practice rules, albuminuria should be tested in T2D within the first year from the diagnosis, while our baseline data refers to the first observations performed in our diabetes centre, and almost none had such determination at that time).

\section{Conclusions}

In conclusion, our findings may offer considerations for the management and prevention of $\mathrm{CV}$ events and mortality in T2D. The evidence of a high mortality risk in newly diagnosed patients, and the relatively low impact of screening for diabetes on mortality [34] emphasizes the need to be more effective in early treatments. These findings also highlight the role of age, both for risk stratification and management, and 
irrespective of the duration of the disease, and reinforce the need for interventions aimed at slowing the decline of renal function immediately after the diagnosis.

\section{Abbreviations}

CKD: Chronic kidney disease

CV: Cardiovascular

CVD: Cardiovascular disease

eGFR: Estimated glomerular filtration rate

T2D: Type 2 diabetes

\section{Declarations}

Ethics approval and consent to participate:

Consent for publication: Not applicable

Availability of data and materials: The dataset analyzed during the current study is available from the corresponding author upon reasonable request.

Competing interests: The Authors declare no conflict of interests related to the present paper.

Funding: This study has been supported by institutional research funds from the University of Pisa.

Authors' contributions: E. B. and F.P. collected and analysed data. A. M. revised the statistical analysis, and contributed to the discussion. A.S. conceived the study and wrote the manuscript. All the Authors approved the final version of the manuscript.

Acknowledgements: Not applicable

Authors' information (optional): None

\section{References}

1. Whiting DR, Guariguata L, Weil C, Shaw J. IDF diabetes atlas: global estimates of the prevalence of diabetes for 2011 and 2030. Diabetes Res Clin Pract. 2011;94:311-21.

2. Tancredi M, Rosengren A, Svensson AM, Kosiborod M, Pivodic A, Gudbjörnsdottir S, et al. Excess mortality among persons with type 2 diabetes. N Engl J Med. 2015;373:1720-732.

3. Gregg EW, Zhuo X, Cheng YJ, Albright AL, Narayan KM, Thompson TJ. Trends in lifetime risk and years of life lost due to diabetes in the USA, 1985-2011: a modelling study. Lancet Diabetes 
Endocrinol. 2014;2:867-74.

4. Orsi E, Solini A, Bonora E, Fondelli C, Trevisan R, Vedovato M, et al.; Renal Insufficiency and Cardiovascular Events (RIACE) Study Group. Haemoglobin A1c variability is a strong, independent predictor of all-cause mortality in patients with type 2 diabetes. Diabetes Obes Metab. 2018;20:1885893.

5. Gaede $\mathrm{P}$, Lund-Andersen $\mathrm{H}$, Parving $\mathrm{HH}$, Pedersen O. Effect of a multifactorial intervention on mortality in type 2 diabetes. N Engl J Med. 2008;358:580-91.

6. Ghouse J, Isaksen JL, Skov MW, Lind B, Svendsen JH, Kanters JK, et al. Effect of diabetes duration on the relationship between glycaemic control and risk of death in older adults with type 2 diabetes. Diabetes Obes Metab. 2019;22:231-42.

7. Gimeno Orna JA, Blasco Lamarca Y, Campos Gutierrez B, Molinero Herguedas E, Lou Arnal LM. Morbidity and mortality cardiovascular risk in dependence of type 2 diabetes duration. Clin Investig Arterioscler. 2014;26:122-30.

8. Holman RR, Paul SK, Bethel MA, Matthews DR, Neil HA. 10-year follow-up of intensive glucose control in type 2 diabetes. N Engl J Med. 2008;359:1577-589.

9. Ford ES, Zhao G, Li C. Pre-diabetes and the risk for cardiovascular disease: a systematic review of the evidence. J Am Coll Cardiol. 2010;55:1310-317.

10. Huang Y, Cai X, Mai W, Li M, Hu Y. Association between prediabetes and risk of cardiovascular disease and all-cause mortality: systematic review and meta-analysis. BMJ. 2016;355:i5953.

11. DeFronzo RA, Abdul-Ghani M. Assessment and treatment of cardiovascular risk in prediabetes: impaired glucose tolerance and impaired fasting glucose. Am J Cardiol. 2011;108:3B-24B.

12. Smith NL, Barzilay JI, Kronmal R, Lumley T, Enquobahrie D, Psaty BM. New-onset diabetes and risk of all-cause and cardiovascular mortality: the Cardiovascular Health Study. Diabetes Care. 2006;29:2012-017.

13. Avogaro A, Fadini GP, Sesti G, Bonora E, Del Prato S. Continued efforts to translate diabetes cardiovascular outcome trials into clinical practice. Cardiovasc Diabetol. 2016;15:111.

14. Dickstein K, Cohen-Solal A, Filippatos G, McMurray JJ, Ponikowski P, Poole-Wilson PA, et al.; SC Committee for Practice Guidelines (CPG). ESC Guidelines for the diagnosis and treatment of acute and chronic heart failure 2008: the Task Force for the Diagnosis and Treatment of Acute and Chronic Heart Failure 2008 of the European Society of Cardiology. Eur Heart J. 2008;29:2388-442.

15. Zoungas S, Woodward M, Li Q, Cooper ME, Hamet P, Harrap S, et al.; ADVANCE Collaborative group. Impact of age, age at diagnosis and duration of diabetes on the risk of macrovascular and microvascular complications and death in type 2 diabetes. 2014;57:2465-474.

16. Wannamethee SG, Shaper AG, Whincup PH, Lennon L, Sattar N. Impact of diabetes on cardiovascular disease risk and all-cause mortality in older men: influence of age at onset, diabetes duration, and established and novel risk factors. Arch Intern Med. 2011;171:404-10.

17. Penno G, Solini A, Bonora E, Orsi E, Fondelli C, Zerbini G, et al.; Renal Insufficiency and Cardiovascular Events (RIACE) Study Group. Defining the contribution of chronic kidney disease to all-cause 
mortality in patients with type 2 diabetes: the Renal Insufficiency And Cardiovascular Events (RIACE) Italian Multicenter Study. Acta Diabetol. 2018;55:603-12.

18. Al-Rubeaan K, Youssef AM, Ibrahim HM. All-cause mortality and its risk factors among type 1 and type 2 diabetes mellitus in a country facing diabetes epidemic. Diabetes Res Clin Pract. 2016;118:130-39.

19. Zghebi SS, Steinke DT, Carr MJ, Rutter MK, Emsley RA, Ashcroft DM. Examining trends in type 2 diabetes incidence, prevalence and mortality in the UK between 2004 and 2014. Diabetes Obes Metab. 2017;19:1537-545.

20. Huo L, Magliano DJ, Rancière F, Harding JL, Nanayakkara N, Shaw JE, et al. Impact of age at diagnosis and duration of type 2 diabetes on mortality in Australia 1997-2011. Diabetologia. 2018;61:1055-63.

21. Jørgensen P, Langhammer A, Krokstad S, Forsmo S. Mortality in persons with undetected and diagnosed hypertension, type 2 diabetes, and hypothyroidism, compared with persons without corresponding disease - A prospective cohort study; The HUNT Study, Norway. BMC Fam Pract. 2017;18:98.

22. Lee G, Kim SM, Choi S,Kim K, Jeong SM, Son JS, et al. The Effect of change in fasting glucose on the risk of myocardial infarction, stroke, and all-cause mortality: a nationwide cohort study. Cardiovasc Diabetol. 2018;17:51.

23. Huang Y, Cai X, Chen P, Mai W, Tang H, Huang Y, et al. Associations of prediabetes with all-cause and cardiovascular mortality: a meta-analysis. Ann Med. 2014;46:684-92.

24. Huang ES, Laiteerapong N, Liu JY, John PM, Moffet HH, Karter AJ. Rates of complications and mortality in older patients with diabetes mellitus: the diabetes and aging study. JAMA Intern Med. 2014;174:251-58.

25. Sattar N, Rawshani A, Franzén S, Rawshani A, Svensson AM, Rosengren A, et al. Age at Diagnosis of Type 2 Diabetes Mellitus and Associations With Cardiovascular and Mortality Risks. Circulation. 2019;139:2228-237.

26. Li Y, Ryu C, Munie M, Noorulla S, Rana S, Edwards P, et al. Association of Metformin Treatment with Reduced Severity of Diabetic Retinopathy in Type 2 Diabetic Patients. J Diabetes Res. 2018;2018:2801450.

27. Lin TC, Hwang DK, Hsu CC, Peng CH, Wang ML, Chiou SH, et al. Protective effect of metformin against retinal vein occlusions in diabetes mellitus - A nationwide population-based study. PLoS One. 2017;12:e0188136.

28. Akın S, Aksoy DY, Cınar N, Aydın K, Karaağaoğlu E, Arıyürek M, et al. Pigment epithelium-derived factor increases in type 2 diabetes after treatment with metformin. Clin Endocrinol (Oxf). 2012;77:852-56.

29. Diabetes Prevention Program Research Group. Long-term effects of lifestyle intervention or metformin on diabetes development and microvascular complications over 15-year follow-up: the Diabetes Prevention Program Outcomes Study. Lancet Diabetes Endocrinol. 2015;3:866-75. 
30. Tanaka S, Kawasaki R, Tanaka-Mizuno S, limuro S, Matsunaga S, Moriya T, et al.; Japan Diabetes Complications Study Group. Severe hypoglycaemia is a major predictor of incident diabetic retinopathy in Japanese patients with type 2 diabetes. Diabetes Metab. 2017;43:424-29.

31. Han J, Li Y, Liu X, Zhou T, Sun H, Edwards P, et al. Metformin suppresses retinal angiogenesis and inflammation in vitro and in vivo. PLoS One. 2018;13:e0193031.

32. Davis TM, Chubb SA, Davis WA. The relationship between estimated glomerular filtration rate trajectory and all-cause mortality in type 2 diabetes: the Fremantle Diabetes Study. Eur J Endocrinol. 2016;175:273-85.

33. Jiang G, Luk AOY, Tam CHT, Xie F, Carstensen B, Lau ESH, et al.; Hong Kong Diabetes Register TRS Study Group. Progression of diabetic kidney disease and trajectory of kidney function decline in Chinese patients with Type 2 diabetes. Kidney Int. 2019;95:178-87.

34. Selph S, Dana T, Blazina I, Bougatsos C, Patel H, Chou R. Screening for type 2 diabetes mellitus: a systematic review for the U.S. Preventive Services Task Force. Ann Intern Med. 2015;162:765-76.

\section{Figures}


1A) eGFR progression over time

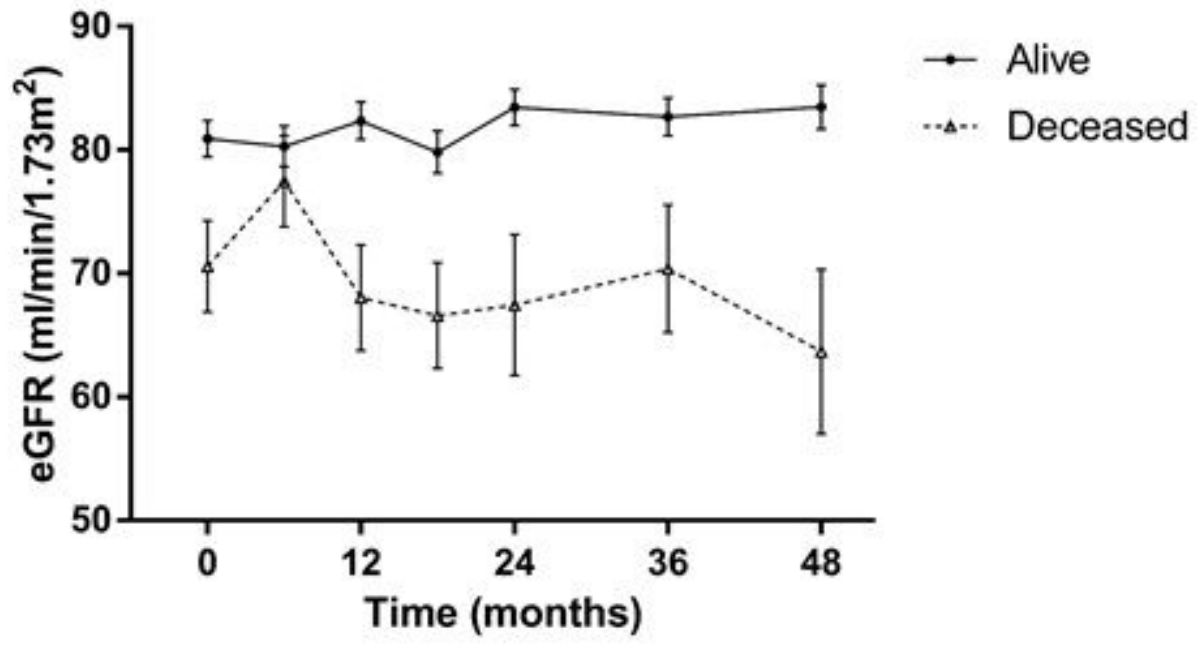

\begin{tabular}{|llllll|}
\hline N & 289 & 281 & 271 & 255 & 242 \\
\hline
\end{tabular}

1B) HbA1c progression over time

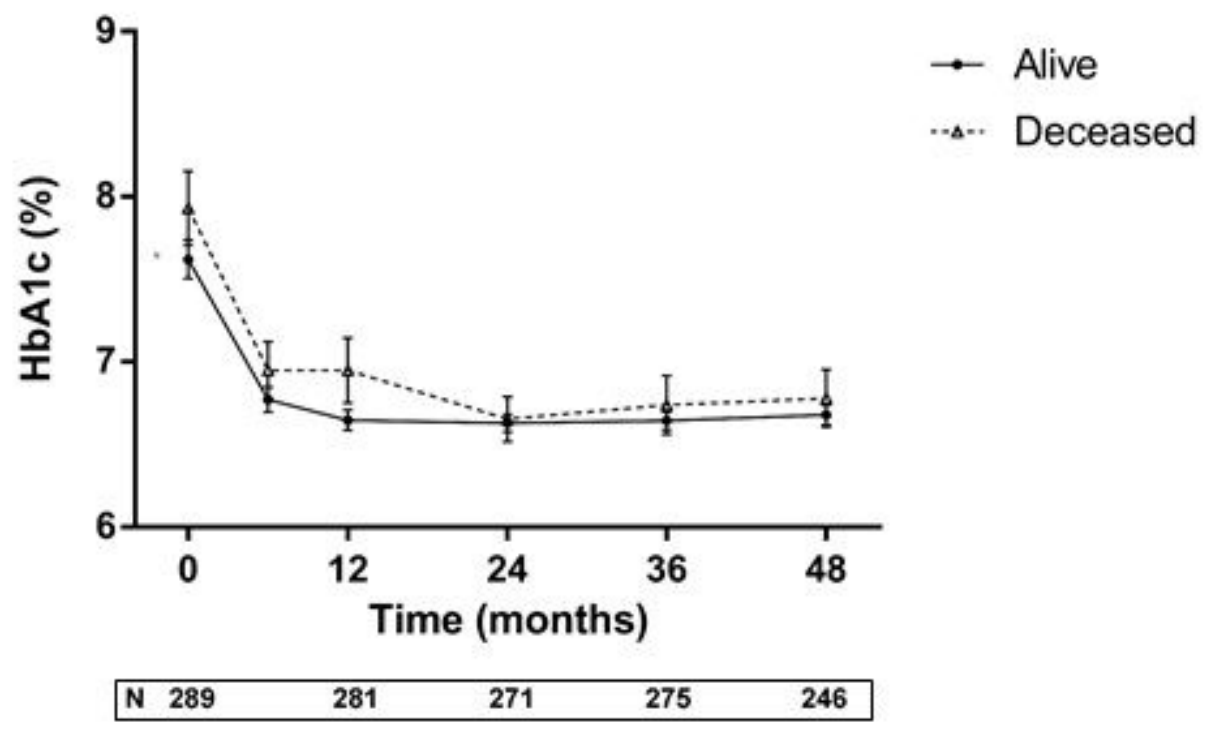

Figure 1

Glomerular function (panel 1A) and HbA1c (panel 1B) over time in relation to mortality. 